\title{
HOW MUCH IS A SMILE WORTH? THE EFFECT OF SMILING FACES IN FOOD RETAIL STORES
}

Quanto vale um sorriso? O efeito de rostos sorridentes em lojas de varejo de alimentos

\section{Leonardo Aureliano-Silva}

E-mail: leonardoaureliano@outlook.com Pós-doutor pela Escola Superior de Propaganda e Marketing; Doutor em Administração pela Universidade Nove de Julho; Professor no Curso de Mestrado Profissional de Gestão em Alimentos e Bebidas da Universidade Anhembi Morumbi e na Graduação da Escola Superior de Propaganda e Marketing. Endereço para contato: Rua Artur Alvim, 123, Vila Mariana, 04018-010, São Paulo, Brasil. https://orcid.org/0000-0003-0884-3849 


\section{Abstract}

The present research tests the emotional contagion theory of an attendant's smiling face on consumer behavior. Five experiments composed of 294 customers were performed in different food retail stores. The results show that the attendant's smiling face has a significant effect on customer judgment about the attendant's disposition to serve customers, and more interestingly, on the price attributed to the products.

Keywords: Smiling face. Food and beverage. Retail.

\section{Resumo}

A presente pesquisa testa a teoria do contágio emocional considerando o rosto sorridente de um atendente sobre o comportamento do consumidor. Cinco experimentos compostos por 294 clientes foram realizados em diferentes lojas de varejo de alimentos. Os resultados mostram que o rosto sorridente do atendente tem um efeito significativo no julgamento do cliente sobre a disposição do atendente para atender, e, mais interessante, sobre o preço atribuído aos produtos. Palavras-chave: Rosto sorridente. Alimentos e bebidas. Varejo.

\section{INTRODUCTION}

The human face acts as a powerful internal and external signaling device (llicic, Kulczynski, \& Baxter, 2018). For example, the use of a smiling face in the service- providing process can lead some customers to have a positive experience with the service delivered by a company (Söderlund \& Rosengren, 2003).

According to Hess and Bourgeois (2010) the act of smiling is a powerful social instrument to influence an individual's behavior. Messinger, Casser, Acosta, \& Cohn (2008) also argue that a smiling face influences another's opinion.

Duchenne (as cited in Scanlon \& Polage, 2011) argued in a seminal paper that when a person smiles, he or she is perceived as sincere. Darwin, Freud, and Piaget also argued that a smile reflects contentment, pleasure, and joy (Messinger et al., 2008), which are important feelings that contribute to make other people feel emotionally better.

Analysts in the marketing area have demonstrated interest in the effect of a smile on consumers' behavior and how this is used in advertisements, by the use of anthropomorphism (Aggarwal \& McGill, 2007). The process of anthropomorphizing products or brands consists of attributing human features to the inanimate object (Spickard \& Guthrie, 1996), in this case, a smile. For example, Tranquinas wafers and Assolan brands, well-known brands in Brazil, have used this strategy to arouse positive feelings in their advertisements and in consumers' purchase experiences (Aggarwal \& McGill, 2007).

llicic, Kulczynski and, Baxter (2018) evidenced that when an endorser presents a smiling facial expression, consumers report more pleasant feelings, and then, the attitude toward to the advertisement, attitude toward the brand and purchase intention are positively influenced.

In the market of the service industry, the interaction between providers and customers is high, thus displaying that positive feelings are an important clue in showing the intention of attending to 
the customer kindly (Wang, Mao, Li, \& Liu, 2016). Grandey, Fisk, Mattila, Jansen, e Sideman (2005), for instance, used videotape simulations to manipulate the authenticity of smiles in a hotel checkin encounter. The research results confirm that the service provider's smile enhances perceptions of friendless and affects satisfaction levels with the hotel service and also the task performance perception.

All of these findings are supported by the emotional contagion theory (Schoenewolf, 1990; Hatfield, Caioppo, \& Rapson, 1993), which is the major background of this study.

Based on these assumptions, the main purpose of this study is to test the effect of the attendant's smile on two dependent variables; the disposition for attending to the customer and the price attributed to products offered by the attendant.

This paper is structured in three parts. The first addresses the theoretical background, and hypotheses, the second details the method and the third covers the discussion, implications and limitations.

\section{SMILE EFFECT AND HYPOTHESES}

The phenomenon of a smile's effect on customers has been neglected in the academic area of restaurant and hospitality management and food service so far. Thus, the use of smile can be a powerful tool to add value to the customer's experience in this market segment.

According to Hatfield et al. (1993), people are influenced by their own emotions and by the emotion of others. In Darwin, Freud, and Piaget studies, smiling is one of the most common nonverbal signals used to establish contact between human beings.

The positive effects of a smile have been found in different contexts. Dion, Berscheid, and Walster (1972), in a classical study on the area of psychology, proved that a smiling face increasing rated attractiveness, sincerity, sociability and competence, when compared to a non-smiling, neutral expression, independent of the individual's beauty traits.

Scharlemann, Eckel, Kacelnik, e Wilson (2001) investigated the role of smiling in bargaining contexts and verified that people are more susceptible to trust in a smiling person than a neutral version of the same person.

Scanlon and Polage (2011) tested the effect of a smile in advertisements and verified that participants significantly preferred smiling faces rather non-smiling faces. A significant preference was also found in their likelihood to purchase products in a Duchenne (as cited in Scanlon \& Polage, 2011) advertisement.

Messinger et al. (2008) showed that the smile is a form that expresses positive emotions. In the case of a service encounter in a restaurant, people consistently interact with each other, thus the act of smiling at the customer can be used as a powerful instrument to influence the customer's experience with the food service, for example (Grandey et al., 2005). 
People who smile are perceived as sincere, honest, and kind; such characteristics that are considered important in attending to customers. Attending attentively to customers in a courteous way, by using a smiling face, can impact the customer's experience in a restaurant (Lin \& Lin, 2011).

Messinger et al. (2008), posited that a smiling face signals a desire for interaction. According to Chang (2006), the impression that customers have about attendants influences their satisfaction and overall service judgment.

All previous studies presented converge on the argument that a smiling face is a signal of positive emotion and as such, has the power of influencing others' feelings positively. Thus, it is hypothesized that: $\mathrm{Hl}$ - The attendant with a smiling face (versus non-smiling face) will be evaluated as having a higher disposition to serve customers, and $\mathrm{H} 2$ - The price attributed to the product will be higher when the attendant presents a smiling face (versus a non-smiling face).

\section{METHOD AND RESEARCH INSTRUMENT STRUCTURE}

To test the smiling effect on customer behavior, five experiments were done using pictures with smiling and non-smiling faces. The choice of the smiling faces was based on Duchenne (as cited in Scanlon \& Polage, 2011).

In total, four pictures with smiling and non-smiling faces from different people were shown to a group ( $n=8$ individuals) using a randomized technique. Then, the pictures were pre-tested in a qualitative approach to check whether the customers considered the individuals in the pictures as having a sincere, smiling face or not. The use of pictures in experiments is a traditional practice and has been reported in different fields of science (Wang, He, \& Liu, 2015; Aggarwal \& McGill, 2007; Lafrance, Hecht, \& Paluck, 2003; Scharlemann et al., 2001).

After that, we asked the other group ( $n=10$ individual) to list characteristics that they consider important for those who want to work as an attendant. The main characteristics mentioned were: the desire to serve customers, kindness, and intention to support customers in all their requests for information.

To evaluate the attendant, affirmatives were created based on the characteristics listed before. They are: The attendant in the picture likes to attend customers; the attendant in the picture shows kindness to customers; the attendant in the picture supports customers in their doubts. These variables were aggregated to be used as dependent variables named as an attendant's disposition for serving customers. All items were measured on a Likert scale of seven points: 1 (completely disagree) to 7 (completely agree).

During the data gathering, the first part of the questionnaire asked the participant to imagine that he/she was shopping at a food retail store, and then was approached by an attendant.

In the sequence, a picture of the attendant was presented. It would be a picture of a smiling or a non-smiling face. The picture with the non-smiling face was used as a control group and the picture with the smiling face as the treatment group. 
The use of pictures to elict emotions are of commom use in the field of psychology (Otta, Lira, Delevati, Cesar, \&, Pires, 1994; Wang et al., 2015). Darwin 1876 (as cited in Wehrle, Kaiser, Schmidt \& Scherer, 2000) was the first scientist to introduce the use of pictures in the study of facial expressions. Psychological science gained important insight into the comprehension of smiling behavior from this.

In the sequence, the respondents evaluated the attendant using one affirmative: The attendant has a great disposition to serve customers. The second question asked about product price: how much would you pay for the product presented by the attendant?

After that, two dichotomous questions confirmed the correct manipulations of the pictures (smiling face versus non-smiling face), through the affirmative: Is the attendant in the picture smiling? Is the attendant's smiling face sincere? The possible answer for both questions was yes, the attendant is smiling and his smiling face is sincere, or it was possible to respond no, for both questions. Those, who responded no were not considered in the analysis.

Finally, the questionnaires were administered through the internet with a random technique, to avoid a demand effect. Data was collected over a period of five months through the internet (from November 2015 to April 28 2016). The total sample in seven experiments was composed of 346 customers. Finally, demographic data was requested.

\subsection{EXPERIMENT 1}

This experiment was conducted to examine whether variations in the attendant's face (smiling face versus non-smiling face) influence the customer's judgment. The gender of the attendant in this study is male. To form the dependent variable, the affirmatives were aggregated and labeled as disposition to serve customers.

\subsubsection{Procedure}

A sample of $(n=67)$ students was invited to participate in this study and asked to assess the attendant's disposition to serve customers. The sample was composed of 35 (52\%) males and 32 (48\%) females. The average age was 28 years old and the average income $\$ 803.90$. Thirty one (49\%) students evaluated the attendant with the smiling face and thirty four (51\%) assessed the attendant with the non-smiling face.

After looking at the picture of the attendant, the participants were asked to comment on whether he was smiling or not. It was controlled by a dichotomous variable - 1 - Yes, the person in the picture is smiling; 2 - No, the person in the picture is not smiling.

To identify differences between the groups (control: non-smiling face versus treatment: smiling face) an analysis of variance was applied. The results indicate a significant effect of the attendant's smile on disposition to serve customers $M_{\text {smiling face }}=4,79 \mathrm{sd}=1,89$ versus $M_{\text {non-smiling face }}=2,81$ sd= 1,80 ; $t(65)=3,560 ; p<0,01$. 
The results of this experiment support the first hypothesis, $\mathbf{H} \mathbf{1}$ - The attendant with a smiling face (versus non-smiling face) will be evaluated as having a higher disposition to serve the customer.

In the second experiment, the effect of the attendant's smiling face (versus. non-smiling face) is used to test its effect on the price attributed to the product.

\subsection{EXPERIMENT 2}

Differently, from the previous study, this experiment tests the effect of the attendant's smiling face on the price attributed to the product. The gender of the attendant is male.

A sample of $(n=76)$ students was recruited to participate in this study. The sample was composed of $39(51 \%)$ males and 37 (49\%) females. The average age was 27 and the average income $\$ 903.15$. Thirty-seven (49\%) students evaluated the attendant with the smiling face and the other thirty-nine $(51 \%)$ the attendant with the non-smiling face. In both conditions, the attendant presented the same product.

A manipulation check of the attendant's smiling face was conducted, as with the previous study. A picture of the attendant was shown and then the respondent informed whether the person in the picture had a smiling-face or not.

The results indicate a significant effect of the attendant's smililing face on a product's price $\left(M_{\text {smiling face }}=U \$ 3.09 \mathrm{sd}=1,48\right.$ vs. $\left.M_{\text {non-smiling face }}=U \$ 2.45 \mathrm{sd}=1,18 ; t(74)=2,127 ; p<0,01\right)$.

The results of this experiment supported the second hypothesis, H2 - The price attributed to the product will be higher when the attendant is presenting a smiling face (versus a non-smiling face).

\subsection{EXPERIMENTS 3, 4 AND 5}

To confirm if the attendant's smiling face also has an effect over other product categories, the experiments were replicated. Results are summarized in Table 1:

Table 1

Experiments 3, 4 and 5 (Prices attributed to the products)

\begin{tabular}{|c|c|c|c|}
\hline \multirow[t]{2}{*}{ Studies } & \multirow[t]{2}{*}{ Products } & \multicolumn{2}{|c|}{ Experimental Conditions $(\mathrm{N}=214)$} \\
\hline & & Smiling face & Non-smiling face \\
\hline $3(n=42)$ & Brazilian food (Tapioca) & $M_{\text {Price }}=2.25(1.44)$ & $M_{\text {Price }}=1.30(2.05)^{* *}$ \\
\hline $4(n=54)$ & Japanese food (Harumaki) & $M_{\text {Price }}=4.75$ (1.69) & $M_{\text {Price }}=2.32(1.52)^{*}$ \\
\hline $5(n=55)$ & Spanish Food (Churros) & $M_{\text {Price }}=1.72(0.45)$ & $M_{\text {Price }}=1.05(0.11)^{* *}$ \\
\hline
\end{tabular}




\section{GENERAL DISCUSSIONS}

The main purpose of this research was to examine the effect of the attendant's smiling face on consumer behavior. Some researchers have investigated the effect of smile on customers, but a gap still existed regarding price attribution, thus this study fills this theory gap.

In the first experiment, the effect of the attendant's smiling face on the customer's perception of the attendant's disposition to serve customers was tested. The results corroborate $\mathrm{HI}$. According to the literature, people with a smiling face are better evaluated in respect to some traits, compared to people with a non-smiling face (Scanlon \& Polage, 2011; Guesguen \& De Gail, 2003). To sum up, when an attendant smiles, customers anticipate their disposition to serve them.

In the following experiments (from 3 to 5) the effect of the attendant's smiling face on the price attributed to the product was tested. The results corroborate H2. This finding contributes to the consumer behavior literature as the phenomenon, from an emotional setting to rational behavior. More interestingly, the act of smiling to customers overlap the rational thinking making them spend more money on their purchases. Therefore, this is the main contribution of this paper.

The influence of smile in social contexts was based on past studies done by Freud, Piaget and Darwin and contemporary scholars in marketing (Choi \& Choo, 2016; Söderlund \& Rosengren, 2003).

Previous studies conducted have not investigated the effect of smile and price in the field of Food Service Studies. This finding contributes to consumer behavior literature in this area of study, because this phenomenon, from an emotional perspective (smile) to rational behavior (undertaking cost-benefit), had not been studied before. Therefore, this is the main contribution of this paper.

According to Piaget and Inhelder (2008), smiles tend to be gratified by the smile of a human partner. This study shows that the smiling face activates a reciprocity mechanism, as explained by emotional contagion theory (Schoenewolf, 1990).

When customers initially evaluate an attendant with a smiling face, he or she is perceived as having more disposition to serve the customers of the food store. This finding aligns with that of Deutsch, LeBaron and Fryer (1987), about smiles and the global perception of a person. Individuals who smile are perceived more positively than non-smiling individuals (Ochs \& Pelachaud, 2012).

To operationalize this study, two hypotheses related to smiling and non-smiling faces were tested, with different products. Before executing the experiments, all smiling pictures were pre-tested. To achieve the objectives of this study all smiles used were considered genuine (Duchenne as cited in Scanlon \& Polage, 2011).

Finally, as seen in previous studies, customers in a positive mood make good evaluations of products and advertisements (Scanlon \& Polage, 2011). Through this study, it was confirmed that when the attendant has a smiling face, the customers' evaluation of his disposition to serve them is higher and also attributes to a higher price for the product. 


\subsection{THEORETICAL AND MANAGERIAL IMPLICATIONS}

This study contributes to consumer behavior theory, specifically in regards to customers' judgments about attendants. This study, even though embryonic, shows that under positive feelings, customers are more likely to spend more money. This indicates that positive feelings surpass the rational process in a customer's evaluation process.

From a managerial perspective, the results support the theory that a smiling face is an important psychological expression of attendants in food stores. Considering the importance of this aspect observed between customers and attendants, a Human Resources Department must pay attention in training employees to be kind, courteous and to use a smiling face to reinforce their desire to serve clients.

\subsection{LIMITATIONS}

This research sheds light on important issues, but some limitations must be noted. First, this research was conducted within the setting of a single culture. Future research must be conducted to test the effect of a smile in different cultures. Secondly, this paper tested the effect of smiling faces on an attendant's disposition to serve customers. It is possible that different results could be found in the hospitality industries, where the interactions between attendants and customers are closer and more intense. Therefore, further research should be conducted with more emphasis on the attractiveness of the attendants or considering the cultures of individualists and collectivist societies.

\section{REFERENCES}

Aggarwal, P., \& McGill, A. L. (2007). Is that car smiling at me? Schema congruity as a basis for evaluating anthropomorphized products. Journal of Consumer Research, 34 (4), 468-479.

Chang, C. C. (2006). When service fails: The role of the salesperson and the customer. Psychology \& Marketing, 23(3), 203-224.

Choi, Y. H., \& Choo, H. J. (2016). Effects of Chinese consumers' relationship benefits and satisfaction on attitudes toward foreign fashion brands: The moderating role of country of salesperson. Journal of Retailing and Consumer Services, 28, 99-106.

Deutsch, F. M., LeBaron, D., \& Fryer, M. M. (1987). What is in a smile? Psychology of Women Quarterly, 11 (3), 341-352.

Dion, K., Berscheid, E., \& Walster, E. (1972). What is beautiful is good. Journal of personality and social psychology, 24(3), 285. 
Grandey, A. A., Fisk, G. M., Mattila, A. S., Jansen, K. J., \& Sideman, L. A. (2005). Is "service with a smile" enough? Authenticity of positive displays during service encounters. Organizational Behavior and Human Decision Processes, 96(1), 38-55.

Gueguen, N., \& De Gail, M. A. (2003). The effect of smiling on helping behavior: Smiling and good Samaritan behavior. Communication reports, 16(2), 133-140.

Hatfield, E., Cacioppo, J. T., \& Rapson, R. L. (1993). Emotional contagion. Current directions in psychological science, 2(3), 96-100.

Hess, U., \& Bourgeois, P. (2010). You smile-I smile: Emotion expression in social interaction. Biological psychology, 84(3), 514-520.

Ilicic, J., Kulczynski, A., \& Baxter, S. M. (2018). How a Smile Can Make a Difference: Enhancing the Persuasive Appeal Of Celebrity Endorsers: Boosting Consumer Perceptions of Celebrity Genuineness Through the Use of a "Duchenne Smile" in Advertising. Journal of Advertising Research, $58(1), 51-64$.

LaFrance, M., Hecht, M. A., \& Paluck, E. L. (2003). The contingent smile: A meta-analysis of sex differences in smiling. Psychological bulletin, 129(2), 305.

Lin, J. S. C., \& Lin, C. Y. (2011). What makes service employees and customers smile: Antecedents and consequences of the employees' affective delivery in the service encounter. Journal of Service Management, 22(2), 183-201.

Messinger, D. S., Cassel, T. D., Acosta, S. I., Ambadar, Z., \& Cohn, J. F. (2008). Infant smiling dynamics and perceived positive emotion. Journal of Nonverbal Behavior, 32 (3), 133.

Ochs, M., \& Pelachaud, C. (2012). Model of the perception of smiling virtual character. Proceedings of the International Conference on Autonomous Agents and Multiagent Systems, 1, 87-94.

Otta, E., Lira, B. B. P., Delevati, N. M., Cesar, O. P., \& Pires, C. S. G. (1994). The effect of smiling and of head tilting on person perception. The Journal of psychology, 128(3), 323-331.

Piaget, J., \& Inhelder, B. (2008). The psychology of the child. New York, US: Basic Books.

Scanlon, A. E., \& Polage, D. C. (2011). The Strength of a Smile: Duchenne Smiles Improve Advertisement and Product Evaluations. Pacific Northwest Journal of Undergraduate Research and Creative Activities, 2 (1), 3.

Scharlemann, J. P., Eckel, C. C., Kacelnik, A., \& Wilson, R. K. (2001). The value of a smile: Game theory with a human face. Journal of Economic Psychology, 22(5), 617-640. 
Schoenewolf, G. (1990). Emotional contagion: Behavioral induction in individuals and groups. Modern Psychoanalysis, 15(1), 49-61.

Söderlund, M., \& Rosengren, S. (2003). The smiling face in marketing appeals and its effects on the customer. SSE/EFI Working Paper Series in Business Administration, 7(1).

Spickard, J., \& Guthrie, S. (1996). Faces in the Clouds: A New Theory of Religion. Sociology of Religion, 57(1), 102.

Wang, Z., He, X., \& Liu, F. (2015). Examining the effect of smile intensity on age perceptions. Psychological reports, $117(1), 188-205$.

Wang, Z., Mao, H., Li, Y. J., \& Liu, F. (2016). Smile big or not? Effects of smile intensity on perceptions of warmth and competence. Journal of Consumer Research, 43(5), 787-805.

Wehrle, T., Kaiser, S., Schmidt, S., \& Scherer, K. R. (2000). Studying the dynamics of emotional expression using synthesized facial muscle movements. Journal of personality and social psychology, $78(1), 105$.

\section{Como citar este artigo:}

ABNT

AURELIANO-SILVA, Leonardo. How much is a smile worth? The effect of smiling faces in food retail stores. RACE, Revista de Administração, Contabilidade e Economia, Joaçaba: Ed. Unoesc, v. 17, n. 3, p. 841-850, set./dez. 2018. Disponível em: <http://editora.unoesc.edu.br/index.php/race>. Acesso em: dia/mês/ano.

\section{APA}

Aurelino-Silva, L. (2018). How much is a smile worth? The effect of smiling faces in food retail stores. RACE, Revista de Administração, Contabilidade e Economia, 17(3), 841-850. Retirado de http:// editora.unoesc.edu.br/index.php/race 